https://nv.nltu.edu.ua

https://doi.org/10.36930/40300520

$@ \bowtie$ Correspondence author

Article received 03.11.2020 p.

Article accepted $18.10 .2020 \mathrm{p}$.

Ye. V. Levus

UDC 004.891

Є. В. Левус, А. О. Полянська

Національний університет "Львівська політехніка", м. Львів, Україна

\title{
АЛГОРИТМ ВИРОБЛЕННЯ КОМПЛЕКСНИХ РЕКОМЕНДАЦІЙ КЛІЕНТАМ ТУРИСТИЧНОЇ ГАЛУЗІ
}

На прикладі туристичної галузі розглянуто розроблений алгоритм вироблення комплексних рекомендацій щодо вибору клієнтами товару чи отримання послуги, що максимально мають відповідати їхнім уподобанням і збереженні клієнтів й прибутків туристичними фірмами. 3'ясовано, що рекомендаційні алгоритми використовують у багатьох інтернет-системах для надання споживачеві поради стосовно вибору клієнтами товару чи отримання послуги, які найбільше відповідають його уподобанням. Незважаючи на значне поширення рекомендаційних систем у різноманітних галузях (електронна комерція, розваги, послуги, соціальні мережі тощо), залишається невирішеним питання, пов'язане з вибором конкретного алгоритмічного підходу для певної області застосування. Наявні алгоритми здебільшого опрацьовують прості об'єкти і не дають змоги якісно вирішити задачу конструювання рекомендації з окремих складових, враховуючи їх сумісність між собою та шукаючи найкращий варіант 3 можливих комбінацій. Побудовано новий алгоритм для комплексної рекомендації на підставі удосконалення алгоритму колаборативної фільтрації за рахунок комбінації методів, заснованих на сусідстві, пам'яті та моделі 3 використанням машинного навчання для коригування ступеня значущості характеристик складових елементів комплексного рішення. Рішення практично реалізовано у формі програмного модуля для рекомендації туристичної подорожі, яка описується місцем відпочинку, маршрутами, готелем та екскурсіями. Особливостями побудованого алгоритму є використання концепції рейтингу користувача для надання збалансованих оцінок елементам турів та коригування коефіцієнтів важливості складових подорожі методом машинного навчання, що дає змогу їх виокремити як параметри моделі рекомендування. Отримані результати порівняно з результатами простіших реалізацій колаборативної фільтрації (засновані на пам'яті та сусідстві). Побудований алгоритм демонструє найкращі результати (30-60) \% рекомендацій, що відповідають очікуванням користувача. Недоліки алгоритму виявляються у разі малої кількості даних і їх розрідженості.

Ключові слова: колаборативна фільтрація; схожість користувачів; коефіцієнт коригування; машинне навчання; комплексна рекомендація.

\section{Вступ}

Прийняття рішення споживачем про придбання товару чи отримання послуги базується на аналізі наявної інформації про них та виборі конкретного варіанта, що $\epsilon$ раціонально обгрунтовано з погляду споживача. Постійний потік інформації зумовлює те, що переглянути корисні й дійсно необхідні позиції $є$ непростим, достатньо громіздким завданням. Споживачеві неочевидно, на які характеристики товару чи надання послуги звертати увагу, на що орієнтуватись, щоб зробити правильний вибір.

Інформаційні технології (спеціальні алгоритми та програмні засоби) дають змогу користувачеві не загубитися у великих обсягах інформації й скористатися не просто можливостями звичайних пошуків чи фільтрів, а отримати рекомендації для придбання товарів чи надання послуг, що будуть автоматично згенеровані на підставі історій придбання подібних товарів чи надання послуг як самим зацікавленим споживачем, так й іншими споживачами $[4,9,12]$.
Застосування алгоритмів вироблення рекомендацій достатньо поширене для простих і типових товарів та послуг (фільми, музика, новини, книги тощо). Існують також рекомендаційні системи, що використовують для складніших типів елементів, наприклад, фінансові інвестиції або подорожі [2]. Вважають, що такі категорії можна розглядати як типові продукти, проте залишається актуальним завданням адаптації та розвитку відомих рекомендаційних алгоритмів для конкретних предметних областей з метою підвищити якість отриманих результатів [13].

Об'єкт дослідження - надання рекомендацій клієнтам для придбання товару чи отримання комплексної послуги.

Предмет дослідження - модифікація алгоритму колаборативної фільтрації та його адаптації для якнайповнішого врахування уподобань користувача та схожості інших користувачів для знаходження комплексного рішення.

Мета роботи - розвиток відомих методів колаборативної фільтрації з адаптацією до комбінації різних

Інформація про авторів:

Левус Євгенія Василівна, канд. техн. наук, доцент, кафедра програмного забезпечення. Email: yevheniia.v.levus@lpnu.ua; https://orcid.org/0000-0001-5109-7533

Полянська Анастасія Олександрівна, магістрант, кафедра програмного забезпечення. Email: yevheniia.v.levus@lpnu.ua

Цитування за Дсту: Левус $Є$. В., Полянська А. О. Алгоритм вироблення комплексних рекомендацій клієнтам туристичної галузі. Науковий вісник НЛтУ України. 2020, т. 30, № 5. С. 122-127.

Citation APA: Levus, Ye. V., \& Polianska, A. O. (2020). Algorithm for developing a complex recommendation through the example of the tourism industry. Scientific Bulletin of UNFU, 30(5), 122-127. https://doi.org/10.36930/40300520 
складових для надання рекомендацій користувачам, що максимально мають відповідати їхнім уподобанням і збереженні клієнтів й прибутків туристичних фірм.

Для досягнення зазначеної мети визначено такі оcновні завдання дослідження:

1) проаналізувати переваги та ефективність рекомендаційних підсистем у популярних інтернет-системах 3 метою виявлення можливостей використання різних модифікацій рекомендаційних алгоритмів для побудови нового алгоритму рекомендування комплексного рішення;

2) розробити алгоритм рекомендування комплексного рішення на підставі комбінації поширених методів колаборативної фільтрації (заснованих на пам'яті, сусідстві, моделі) 3 використанням коефіцієнтів значущості окремих складових і їх коректуванням методом машинного навчання;

3) виявити основні сутності на основі емпіричних даних для опису моделі туристичної подорожі, програмно реалізувати розроблений алгоритм та методи колаборативної фільтрації, створити базу даних користувачів для оцінки результатів;

4) проаналізувати отримані результати з погляду якості наданих рекомендацій для різних тенденцій (i їх відсутності) стосовно схожості користувачів та недоліків для граничних випробувань.

Наукова новизна отриманих результатів дослідження - розвиток відомих методів колаборативної фільтрації та адаптації алгоритму рекомендування для предметних областей, що використовують складені об'єкти.

Практична значущість результатів дослідження побудовані алгоритми можна використовувати в туристичних агентствах для надання потенційним клієнтам поради стосовно вибору клієнтами товару чи отримання послуги, які в умовах карантинних обмежень як ніколи зацікавлені в оптимальних рішеннях, що максимально мають відповідати їх уподобанням, водночас, фірми, що надають туристичні послуги - у збереженні клієнтів та прибутку.

Матеріали та методи дослідження. У популярних веб-системах з рекомендуванням достатньо часто враховується подібність користувачів або товарів/послуг для надання порад. Один із найпопулярніших методів, що базуються на схожості користувачів чи послуг, $\epsilon$ алгоритм колаборативної фільтрації $[13,15]$. Загалом його можна описати такою формулою:

$$
\boldsymbol{R}=\left\{\boldsymbol{r}_{i}=\left\{\boldsymbol{r}_{u, i}=k \cdot \sum_{u^{\prime}=1}^{U} \operatorname{sim}\left(u, u^{\prime}\right) \cdot \boldsymbol{r}_{u^{\prime}, i}, u^{\prime}=\overline{1, U}\right\} ; i=\overline{1, N}\right\},
$$

де: $r_{u, i}$ - виставлена оцінка $u$-тим користувачем $i$-му товару/послузі; $u$ - даний користувач, оцінка якого передбачається; $u^{\prime}$ - інший користувач, що $є$ схожим із даним; $\operatorname{sim}()-$ функція, що визначає обрану величину схожості двох користувачів; $U$ - кількість користувачів; $N$ - кількість товарів/послуг; $k$ - коефіцієнт норми.

Замість величини схожості (sim) може використовуватись рейтинг користувача відносно даного або певні параметри користувача, що ідентифікуватимуть його важливість. Значення цього параметра залежить від обраного підходу алгоритму колаборативної фільтрації. Коефіцієнт норми $(k)$ впливає на результат та може змінювати його істотно залежно від багатьох факторів, може обиратися експериментально для точності. Коефіцієнт норми приймають рівним одиниці, якщо відбувається абстрагування від зовнішніх впливів.
Використана процедура обчислення схожості користувачів складається з таких кроків.

1. Ініціалізація коефіцієнта схожості користувача $u_{1}$ i $u_{2}$ значенням 1 .

2. Порівняння об'єктів преференцій користувачів $u_{1}$ i $u_{2}$. Якщо преференція збігається, то коефіцієнт схожості множиться на відповідний коефіцієнт, значення якого береться з бази даних. База даних формується емпірично, коефіцієнти означають пріоритетність характеристик подорожі.

3. Для всіх користувачів $u_{3}, \ldots, u_{U}$ виконуються описані вище дії.

4. Виконується сортування за цим коефіцієнтом у спадному порядку подібності i обираються ті, що $\epsilon$ найбільш схожими до даного користувача.

Запропонований алгоритм формування рекомендації складається $з$ таких дій:

1) Пошук локацій, що відповідає вимогам користувача, здійснюється на підставі значення відповідності та коефіцієнта важливості. У разі, якщо локація відповідає преференціям користувача, то значення відповідності множиться на відповідний коефіцієнт важливості, який вказує, наскільки ця характеристика істотна для користувача. У такий спосіб отримуємо коефіцієнти відповідності для всіх локацій.

2) Пошук схожих до даного користувачів спочатку відбувається за процедурою описаною тут вище. Якщо схожий користувач оцінював локації, для яких розраховувалося значення відповідності (обчислення 1), то змінюється значення відповідності множенням на коефіцієнт $\frac{1}{n} \sum_{u s \in U}\left(a r \cdot \frac{u r^{2}}{2}\right)$, де $u s$ - надана порада користувачу, що було обрана ним та містить дану складову; US - множина наданих порад користувачам, що були обрані ними та включають дану складову; $a r$ - оцінка складової туру у цій пораді; $u r$ - рейтинг поточного користувача; $n$ - кількість порад користувачам, що розглядаються. Рейтинг базується на активності користувача (кількості замовлень, коментарів та наданих оцінок), а також на кількості схожих до нього користувачів, що ідентифікуватиме, наскільки він $є$ типовим.

3) Сортуємо локації за коефіцієнтом відповідності у порядку спадання і обираємо задану кількість 3 найкращим коефіцієнтом.

4) Для обраних локацій, що відповідають уподобанням користувача, виконуємо аналогічні обчислення 1)-3) для маршрутів, готелів і екскурсій. Вибір маршрутів, готелів і екскурсій здійснюється зі списку асоційованих із обраною локацією. Унаслідок отримаємо список локацій і для кожної $з$ них - списки маршрутів, готелів i екскурсій, які найточніше відповідають уподобанням користувача.

5) Конструюємо $з$ отриманих списків рекомендації у всіх можливих комбінаціях і сортуємо за загальним рейтингом (сума значень відповідності кожної складової) у порядку спадання. Зі списку формуємо підсписок найрейтинговіших.

Для уточнення поведінки рекомендаційної системи використовують метод машинного навчання, за допомогою якого відбувається коригування коефіцієнта важливості характеристик туристичної подорожі для кожного користувача (рис. 1). Наприклад, користувач вважає, що наявність преференції паркування машини важливіші, ніж преференції гарного виду з вікна готелю тощо. Процедура коригування виконується для врахування того, що не всі преференції однаково важливі і їх 
значущість не $\epsilon$ завжди явною. Запропоновано використання методу машинного навчання для виявлення неявних уподобань користувача у разі, коли користувач вносить у систему одні 3 характеристик подорожей як істотні, а насправді історія вибору турів суперечить цьому і навпаки.

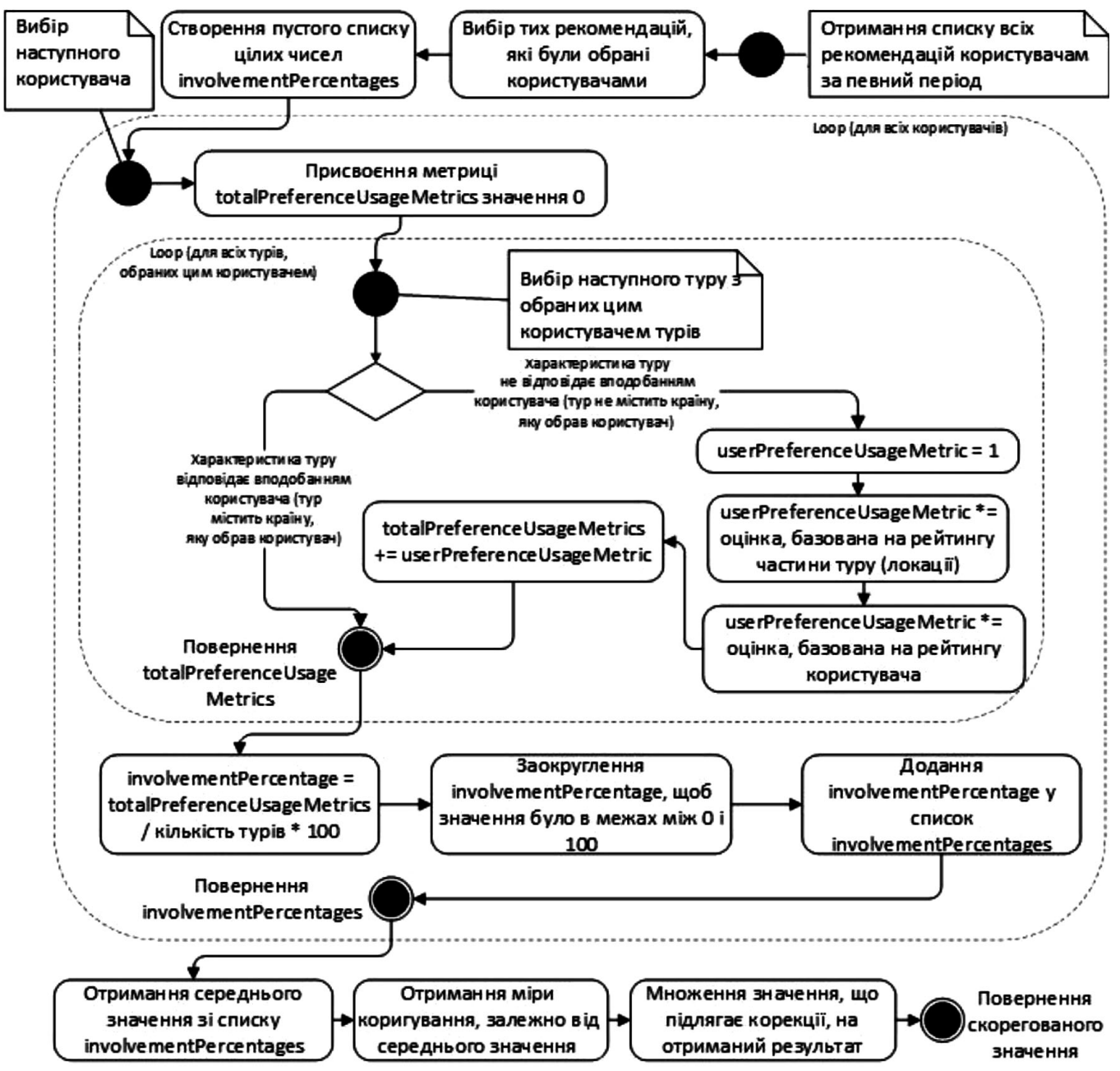

Рис. 1. Схема алгоритму коригування коефіцієнта важливості

Підсистема машинного навчання періодично опрацьовує списки рекомендацій, що були надані користувачам за новий проміжок часу, та коригує коефіцієнти важливості.

Особливостями запропонованого алгоритму вироблення рекомендації, як комплексного рішення, $\epsilon$ :

- використання концепції рейтингу користувача для надання збалансованих оцінок елементам турів;

- виокремлення параметрів моделі рекомендування, які можна задавати зовні або які будуть змінюватись відповідно до конкретних причин.
Аналіз останніх досліджень та публікацій. Проведено огляд інтернет-систем торгівлі та інтернет-сервісів різного призначення 3 рекомендаційною компонентою $[3,5,6,10,12]$. Наявні методи рекомендування у розглянутих системах (табл. 1) не дають змоги конструювати рекомендацію з окремих складових, враховуючи їх сумісність між собою та шукаючи найкращий варіант 3 можливих комбінацій.

Найчастіше у літературі, як ефективний метод рекомендування, пропонують рішення гібридизації різних рекомендаційних алгоритмів та їх модифікації.

Табл. 1. Порівняння методів рекомендування у популярних системах

\begin{tabular}{|c|c|c|c|c|c|}
\hline Критерій порівняння & NETFLIX & YOUTUBE & ITUNES & SPOTIFY & AMAZON \\
\hline Точність поділу на групи товарів & Висока & Середня & Середня & Висока & Висока \\
\hline Точність поділу на групи користувачів & Висока & Середня & Низька & Низька & Висока \\
\hline Машинне навчання & $\epsilon$ & $\epsilon$ & $\epsilon$ & $\mathrm{E}$ & $\mathrm{E}$ \\
\hline Використання рейтингу користувача & Немає & $\epsilon$ & Немає & Немає & $\epsilon$ \\
\hline Створення індивідуальних рекомендацій & Немає & Немає & Немає & $\epsilon$ & $\epsilon$ \\
\hline Використання матричного підходу & $E$ & Немає & Немає & $E$ & $E$ \\
\hline Лінгвістичний аналіз контенту & Немає & $\epsilon$ & $\epsilon$ & Немає & Немає \\
\hline $\begin{array}{l}\text { Відсоток залучення рекомендацій користу- } \\
\text { вачами }\end{array}$ & $80 \%$ & Вище $70 \%$ & $\begin{array}{c}\text { Немає відкритої } \\
\text { інформації }\end{array}$ & $\begin{array}{c}\text { Немає відкритої } \\
\text { інформації }\end{array}$ & $35 \%$ \\
\hline Задоволеність користувачів & Висока & Середня & Середня & Дуже висока & Середня \\
\hline
\end{tabular}

У роботі [11] описано значення можливості визначення подібності користувачів для електронної комерції й різні варіанти методу, заснованого на сусідстві та їх можливі імплементації. Автор роботи [2] досліджує варіант рекомендаційного алгоритму, що базується на подібності між виробами та надає рекомендації на підставі їх визначених особливостей і попередніх рішень користувачів веб-системи. Актуальною $є$ пропозиція 
доповнювати класичний підхід до алгоритму колаборативної фільтрації, заснованому на сусідстві, врахуванням подібності користувачів системи між собою. У роботі [14] використано порівняння користувачів між собою, запропоновано ідею використання рейтингу користувача для якіснішої та точнішої оцінки схожості клієнтів між собою. Така концепція призводить до ускладнення алгоритму, але є необхідною для підвищення ефективності системи. Гібридний підхід до колаборативної фільтрації, що об'єднує позитивні ознаки підходів, заснованих на сусідстві та на моделі, зменшує вплив на процес рекомендування їхніх основних уразливостей $[1,7,8]$.

У літературі описано різні варіанти модифікації рекомендаційних алгоритмів $[1,2,7,8,11,14]$, більшість 3 яких використовує колаборативну фільтрацію та адаптовані до певних предметних областей (комерція, індустрія розваг, банківська справа) $[13,15]$. Якість отриманих рекомендацій у модифікованих, гібридних алгоритмах досягається за рахунок точнішого врахування значущості рейтингу схожих користувачів, приналежності користувачів до одних категорій (зокрема, демографічні показники), виявлення схожості за різними методиками, виокремлення параметрів конкретних пара- метрів виробів, користувачів або зовнішніх впливів, що істотно впливатимуть на рішення людей тощо. Усі модифікації виконуються з метою отримання рекомендацій, що відповідали б очікуванням користувачів. Окрім цього, гібридизація рекомендаційних алгоритмів дає змогу мінімізувати недоліки методів, заснованих на пам'яті, сусідстві, моделі. 3 іншого боку, цей підхід $є$ складним і вартісним у реалізації та застосуванні, що вимагає розроблення спеціальних методів для зменшення цих недоліків.

\section{Результати дослідження та їх обговорення}

Модель туристичної подорожі складається 3 чотирьох окремих частин - місць відпочинку (англ. Location Preference), маршрутів (англ. Route Preference), готелів (англ. Hotel Preference) та екскурсій (англ. Excursion Preference) (рис. 2).

Відповідно до вподобань схожих користувачів вибираються та об'єднуються в рекомендації зазначені частини туристичних подорожей. Схожість користувачів визначається, базуючись на їх вподобаннях. Така техніка визначення подібності використовується у більшості сучасних рекомендаційних систем: Netflix, YouTube, Spotify, ITunes та ін.

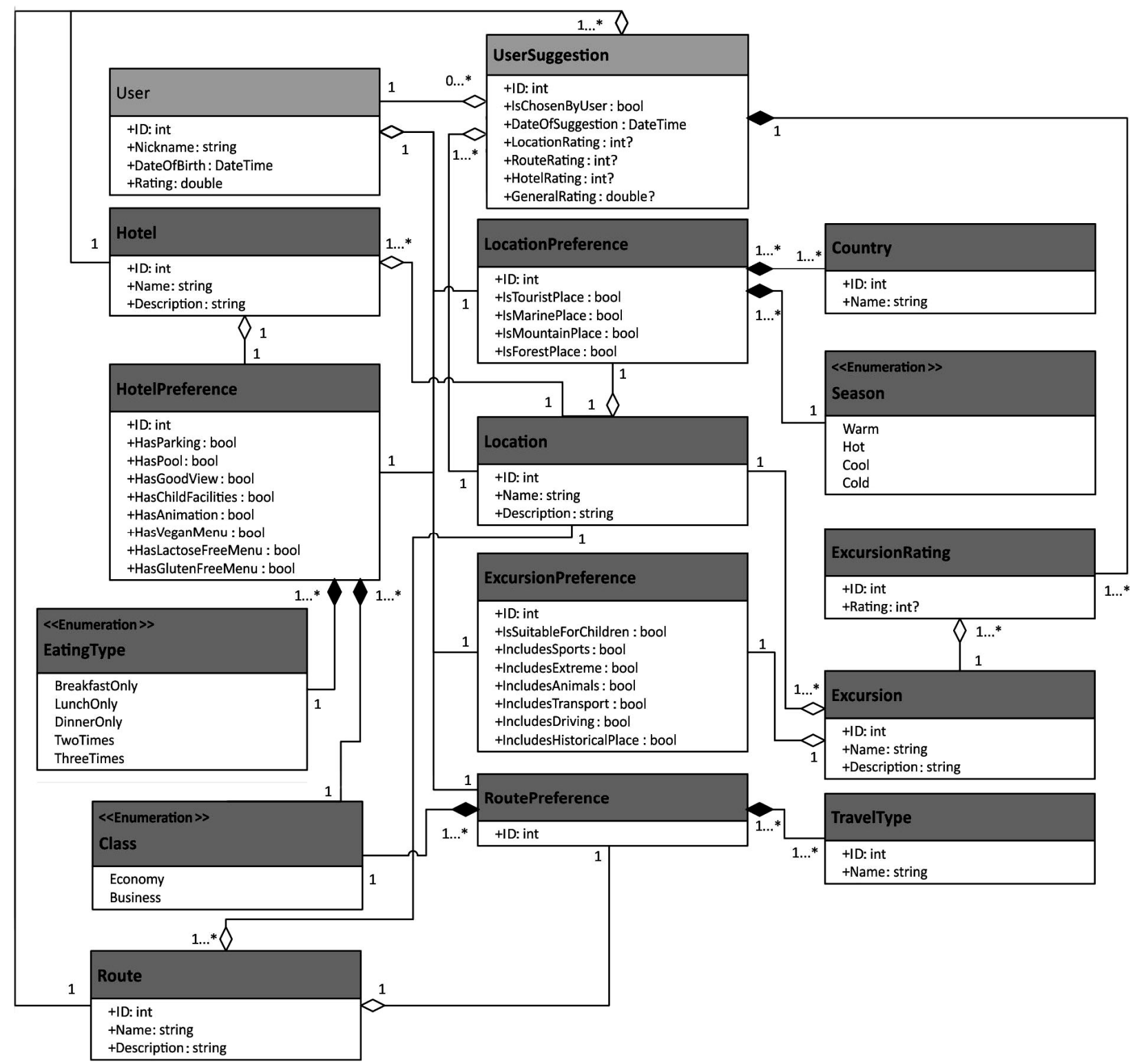

Рис. 2. Діаграма сутностей моделі туристичної подорожі 
Табл. 2. Приклад вхідних даних

\begin{tabular}{|c|c|c|c|c|c|}
\hline \multirow{2}{*}{ Клієнт } & \multirow{2}{*}{$\begin{array}{l}\text { Схожих ко- } \\
\text { ристувачів }\end{array}$} & \multicolumn{4}{|c|}{ Вподобання стосовно } \\
\hline & & локацій & готелю & маршруту подорож & екскурсій \\
\hline $\begin{array}{l}\text { Ім'я: Софія } \\
\text { Вік: } 45\end{array}$ & 10 & $\begin{array}{l}\text { Країна: Україна, Сгипет } \\
\text { Сезон: Тепла пора року } \\
\text { Туристичне місие } \\
\text { Море, Лісиста місцевість }\end{array}$ & $\begin{array}{l}\text { Клас: Економ } \\
\text { Харчування: Лише вечеря } \\
\text { Безглюте-нове меню } \\
\text { Паркування }\end{array}$ & $\begin{array}{l}\text { Дорога: Потяг, Авто- } \\
\text { бус, Літак } \\
\text { Клас: Бізнес }\end{array}$ & $\begin{array}{c}\text { Контакт із тваринами } \\
\text { Внесено транспорт }\end{array}$ \\
\hline
\end{tabular}

Користувач визначає свої вподобання стосовно частин туристичної подорожі, заповнюючи чотири відповідні анкети - побажання щодо певних характеристик. Після цього в системі використовуються об'єкти вподобань (preferences), асоційовані з даним користувачем, реалізовані через булеві величини, переліки, текстові описи. Сутності системи, що позначають кожну з частин туристичної подорожі, також мають асоційовані із ними об'єкти вподобань. У цьому разі такі об'єкти відіграють роль опису частини туристичної подорожі.

Міра подібності між описом складової туристичної подорожі та вподобанням користувача щодо даної частини туру визначає, чи може складова бути рекомендована у кожному конкретному випадку.

Розроблений алгоритм реалізовано у вигляді webмодуля для надання рекомендації туристичної подорожі, яка описується складовими (локація, маршрут, готель, екскурсії). Web-система реалізована технологією C\#, для взаємодії із базою даних використано Microsoft SQL Server. 3 допомогою розробленого програмного забезпечення проведено обчислювальні експерименти (табл. 2, 3) для 100 користувачів та 250 рекомендацій туристичних подорожей, використано обмеження щодо локацій -3 , маршрутів, готелів, екскурсій для кожної локації - 5, 5 та 3 відповідно, кількість схожих користувачів - до 10.

Після пошуку схожих користувачів і вироблення рекомендацій системою відбувається виявлення неявних уподобань користувачів, що дає змогу ітераційно уточнити поведінку рекомендаційної компоненти (див. табл. 3).

Табл. 3. Приклад результатів роботи рекомендаційної системи

\begin{tabular}{|c|c|c|c|}
\hline Алгоритм & $\begin{array}{c}\text { Кількість от- } \\
\text { риманих ре- } \\
\text { комендацій, } \\
\text { всього }\end{array}$ & $\begin{array}{c}\text { Кількість реко- } \\
\text { мендацій, що від- } \\
\text { повідало очіку- } \\
\text { ванням користу- } \\
\text { вача } \\
\end{array}$ & $\begin{array}{l}\text { Якість ре- } \\
\text { коменду- } \\
\text { вання, \% }\end{array}$ \\
\hline Базовий & 9 & 2 & 22,2 \\
\hline $\begin{array}{c}\text { Заснований на } \\
\text { пам'яті }\end{array}$ & 9 & 2 & 22,2 \\
\hline $\begin{array}{c}\text { Заснований на } \\
\text { сусідстві }\end{array}$ & 15 & 8 & 53,3 \\
\hline $\begin{array}{c}\text { Модифікація, } \\
1 \text { ітерація }\end{array}$ & 16 & 10 & 62,5 \\
\hline $\begin{array}{c}\text { Модифікація, } \\
10 \text { ітерація }\end{array}$ & 30 & 22 & 73,3 \\
\hline
\end{tabular}

Розроблене програмне забезпечення може використовуватися як практичний інструмент проведення обчислювальних експериментів для виявлення залежностей між різними характеристиками, вхідними та вихідними даними рекомендаційних алгоритмів.

Обговорення результатів дослідження. Результати, отримані модифікованим алгоритмом (рис. 3), порівняли $з$ результатами простіших популярних реалізацій колаборативної фільтрації (засновані на пам'яті та сусідстві) та базовим рекомендаційним алгоритмом, який здійснює порівняння на підставі тільки вказаної інформації користувачем. Базовий алгоритм не орієнтується ні на рейтинги користувачів, ні на схожих користувачів.

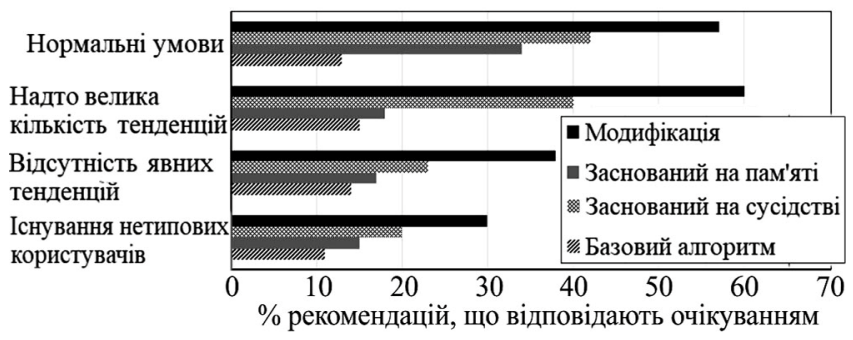

Рис. 3. Результати застосування методів вироблення рекомендацій

Порівняння здійснено для випадків: 1) типові умови, коли у користувача є достатньо схожих користувачів, відповідно є складові туристичної подорожі, що відповідають його вподобанням. Тобто, наявні дані, з яких можна вибирати, щоб сконструювати якісні рекомендації; 2) у користувача багато схожих користувачів, $є$ багато складових туристичної подорожі, що відповідають його вподобанням; 3) у користувача мало схожих користувачів, є небагато складових туристичної подорожі, що відповідають його вподобанням. Тобто, не так багато варіантів для вибору і конструювання рекомендацій; 4) користувачі, для яких відсутні явні тенденції, які мають характеристики сильно відмінні від решти або неочевидні, уподобання яких нетипові, часом суперечливі.

Модифікований алгоритм демонструє найкращі результати - від 30 до 60 \% рекомендацій, що відповідають очікуванням користувача. Недоліки алгоритму виявляються у випадках малої кількості даних і розрідженості даних.

\section{Висновки}

Актуальним дослідженням $є$ адаптація рекомендаційних алгоритмів до конкретних предметних областей та їх розвиток $з$ метою підвищити якість отриманих результатів. У роботі описано рішення стосовно рекомендаційного алгоритму для туристичної галузі, для якої особливістю $є$ вироблення комплексної рекомендації, що відрізняє іiі від інших предметних областей, для яких розроблено багато модифікованих та гібридних алгоритмів вироблення рекомендацій.

1. Виявлено найпоширеніші методи, що використовуються у рекомендаційних підсистемах популярних інтернет-систем 3 метою отримання якісних рекомендацій (гібридизація методів колаборативної фільтрації, рейтингування усіх користувачів, машинне навчання).

2. Розроблено алгоритм вироблення рекомендації для кліснтів туристичної галузі на підставі комбінації методів колаборативної фільтрації, заснованих на пам'яті, сусідстві та моделі 3 використанням машинного навчання для коригування ступеня значущості характеристик складових елементів комплексного рішення.

3. Рішення програмно імплементовано у вигляді web-cистеми. Отримані результати для 100 користувачів порів- 
няно $з$ результатами алгоритмів колаборативної фільтрації, заснованих на пам'яті та сусідстві.

4. Отримані результати засвідчують перспективність досліджень та вказують на потребу опрацювання особливих випадків - малої кількості та розрідженості даних.

5. Розроблений алгоритм може бути використано для вироблення рекомендацій для інших предметних областей, для яких характерні складені об'єкти.

\section{References}

1. Aggarwal, C. (2016). Neighborhood-Based Collaborative Filtering. Retrieved from: https://www.researchgate.net/publication/314921150 Neighborhood-Based Collaborative Filtering.

2. Bahramian, Z., Abbaspour, R., \& Claramunt, T. (2018). Geospatial Collaborative Tourism Recommender Systems. In book: GIS Applications in the Tourism and Hospitality Industry. https://doi.org/10.4018/978-1-5225-5088-4.ch010

3. Blattmann, J. (2018). Netflix: Binging on the Algorithm. Retrieved from: https://uxplanet.org/netflix-binging-on-the-algorithm-a3a74a6c1f59

4. Bobadilla, J., Ortega, F., Hernando, A., \& Bernal, J. (2012). A collaborative filtering approach to mitigate the new user cold start problem. Knowledge-Based Systems, 26, 225-238. https://doi.org/10.1016/j.knosys.2011.07.021

5. Brinton, C., \& Chiang, M. (2019). Netflix Recommendation System. Retrieved from: https://www.coursera.org/lecture/networks-illustrated/netflix-recommendation-system-TYOZV.

6. Chhabra, S. (2017). Netflix says 80 percent of watched content is based on algorithmic recommendations. Retrieved from: https://mobilesyrup.com/2017/08/22/80-percent-netflix-showsdiscovered-recommendation/

7. Christakou, Ch., Vrettos, S., \& Stafylopatis, A. (2007). A hybrid movie recommender system based on neural networks. Internati- onal Journal on Artificial Intelligence Tools, 05(16), 771-792. https://doi.org/10.1142/S0218213007003540

8. Dommeti, R. (2007). Neighborhood Based Methods For Collaborative Filtering. Retrieved from: http://cs229.stanford.edu/proj2007/Dommeti-NeighborhoodBasedMethodsForCollaborativeFiltering.pdf.

9. Ge, M., Delgado-Battenfeld, C., \& Jannach, D. (2010). Beyond accuracy: Evaluating recommender systems by coverage and serendipity. Proceedings of the fourth ACM conference on Recommender systems - RecSys 10, 257-260. https://doi.org/10.1145/1864708.186476110

10. Koul, A. (2019). Understanding YouTubes Algorithm in 2019. Retrieved from: http://social.colostate.edu/2019/04/02/youtube-algorithm/.

11. Kumar, A. (2020). YouTubes Recommendation Engine: Explained. Retrieved from: https://hackernoon.com/youtubes-recommendation-engine-explained-40j83183.

12. Linden, G., Smith, B., \& York, J. (2003). Amazon.com recommendations: item-to-item collaborative filtering. IEEE Internet Computing, 7(1), 76-80. https://doi.org/10.1109/mic.2003.1167344

13. Lytvyn, V., Vysotska, V., Shatskykh, V., et. al. (2019). Design of a recommendation system based on collaborative filtering and machine learning considering personal needs of the user. EasternEuropean Journal of Enterprise Technologies, 4(2(100)), 6-28. https://doi.org/10.15587/1729-4061.2019.175507

14. Tufekci, Z. (2019). YouTube Has a Video for That. Scientific American 320, $4, \quad 77$. https://doi.org/10.1038/scientificamerican0419-7713

15. Xiaoyuan, Su, Taghi, M., \& Khoshgoftaar, A. (2009). Survey of Collaborative Filtering Techniques. Hindawi Publishing Corporation, Advances in Artificial Intelligence archive, 1-19. https://doi.org/10.1155/2009/421425

Ye. V. Levus, A. O. Polianska

Lviv Polytechnic National University, Lviv, Ukraine

\section{ALGORITHM FOR DEVELOPING A COMPLEX RECOMMENDATION THROUGH THE EXAMPLE OF THE TOURISM INDUSTRY}

The process of choosing a product or service by customers in e-commerce systems is automated using recommendation algorithms. Recommendation methods in online trading systems and services for various purposes (in particular, Netflix, YouTube, iTunes, Spotify, Amazon) do not allow constructing a recommendation from separate components, taking into account their compatibility with each other and looking for the best possible combination. A new algorithm for a complex recommendation based on the development of a collaborative filtering algorithm through a combination of neighbourhood, memory, and model-based methods is proposed. It also uses machine learning to adjust the component characteristics significance of a complex solution. The algorithm is adapted and programmatically implemented for the tourism industry. The model of a tourist trip is described by such components as Location Preference, Route Preference, Hotel Preference and Excursion Preference, which, in their turn, have a compositional structure. To consider the implicit user preferences, the significance adjustment coefficients for the trip components were used. The calculation of these coefficients is based on machine learning, which enables considering the hidden preferences of the user more accurately. Various methods to generate a tourist trip recommendation for the user that were implemented are as follows: a modified algorithm, methods of collaborative filtering based on memory and neighbourhood, a selection algorithm based only on information from the user. The results are obtained for the input data from 100 users in typical conditions, in cases of a large number of trends, the absence of obvious trends and the existence of atypical users. The modified algorithm shows the best results - from 30 to 60 percent of the recommendations that meet user expectations. The disadvantages of the algorithm are found in cases of small amounts of data and sparse data.

Keywords: collaborative filtering algorithm; machine learning; complex recommendation; similar users. 